\title{
Ocultamento e silenciamento familiares no cuidado à criança em terapia antiretroviral
}

\author{
Family members' concealing and silencing in the care of children under antiretroviral therapy \\ Ocultamiento y silenciamiento del familiar en el cuidado al niño en la terapía antiretroviral
}

\section{Antônio Marcos Tosoli Gomes', Ivone Evangelista Cabral'}

'Universidade do Estado do Rio de Janeiro. Faculdade de Enfermagem. Rio de Janeiro, RJ

Submissão: 07/06/2009

Aprovação: 19/06/2010

\section{RESUMO}

Definiu-se como objetivos desse estudo desvelar o cotidiano de cuidadores de criança em terapia antiretroviral e analisar as dimensões presentes na implementação do cuidado medicamentoso. De cunho Qualitativo, desenvolveu-se duas dinâmicas do concreto do Método Criativo-Sensível com sete sujeitos, realizando-se análise de discurso. Os resultados apontam a existência de um cotidiano perpassado pelo ocultamento e silenciamento. O ocultamento é explicitado pelas regularidades lingüísticas em Que HIV/Aids não aparece; também é percebido na organização do cotidiano, ao não expor a soropositividade. O silenciamento é encontrado basicamente na relação com a criança, Quando seus Questionamentos não são respondidos. Conclui-se que o silenciamento e o ocultamento necessitam ser abordados pelo enfermeiro em sua intervenção no cuidado e na educação em saúde.

Descritores: HIV; Criança; Enfermagem pediátrica; Educação em saúde.

\section{ABSTRACT}

The aims of this paper were unveiling the caregiver's everyday life of caring for children under antiretroviral therapy (ARVT), and analyzing the dimensions of care them. Qualitative research was conducted with a creative-sensitive method including seven family members and data were treated through discourse analysis. These family members' everyday life in the medication implementation was marked by concealing and silencing. The first one was represented by linguistic regularities, as expressions and acronyms do not appear in their enunciation, and also in the way their lives are organized facing stigma and bias related to the ARVT. The last one occurred in the relationship with children, as when family members were Questioned about the medication, they answered in an evasive way. Concealing and silencing related to child HIV/AIDS are themes which need to be approached by nurses in their caring and health education interventions. Key words: HIV; Child; Pediatric nursing; Health education.

\section{RESUMEN}

Fueron definidos, entonces, como objetivos de este estudio a revelar el cotidiano existencial de cuidadores de niños en terapia antiretroviral y analizar las dimensiones presentes en sus situaciones existenciales en la implementación del cuidado medicamentoso. De carácter cualitativo, fueron desarolladas dos dinámicas del concreto del método Criativo-Sensible con siete ciudadanos, realizándose análisis del discurso posteriormente. Los resultados señalan la existencia de un cotidiano existencial perpassado por el ocultamiento y el silenciamiento. El ocultamiento puede se evidenciado por las regularidades linguísticas en que no aparece HIV/AIDS; también se percibe en la organización del cotidiano, en la tentativa de no exhibir soropositividad. El silenciamiento se encuentra basicamente en la relación con el niño, donde sus dudas no son respondidos. Se concluye que el silenciamiento y el ocultamiento son temas Que necesitan ser discutidos por el enfermero en su intervención en el cuidado y en la educación en salud.

Descriptores: VIH; Niño; Enfermería pediátrica; Educación en salud.

AUTOR CORRESPONDENTE Antônio Marcos Tosoli Gomes. Universidade do Estado do Rio de laneiro, Centro Biomédico, Faculdade de Enfermagem. Boulevard 28 de Setembro, 157/70 andar. Vila Isabel. CEP 205 I I-130. Rio de Janeiro, RI. 


\section{INTRODUÇÃO}

A Síndrome da Imunodeficiência Adquirida (AIDS) e o seu agente etiológico, o vírus da Imunodeficiência Humana (HIV), foram reconhecidos como um desafio à ciência, ao mesmo tempo em Que são compreendidos como um drama humano e social pelas famílias Que possuem uma criança infectada. As crianças adeuiriram importância epidemiológica a partir dos anos 1990, em decorrência das transformações simultâneas Que aconteceram com o perfil epidemiológico do HIV/Aids em geral. Dentre essas, destacam-se o aumento da infantilização do HIV/Aids como efeito da sua feminização, heterossexualização e pauperização da síndrome ${ }^{(1)}$.

O Ministério da Saúde ${ }^{(2)}$ disponibilizou números comparativos de prevalência referentes a dois períodos: 1983-1992 e 19922004. No primeiro, foram notificados 1.760 casos e no segundo, 10.917. Ressalta-se Que ao longo dos últimos I I anos, houve um crescimento de Quase 500\% dos casos de HIV/Aids infantil, justificando os diferentes aspectos epidemiológicos da síndrome no curso do tempo.

Com essa elevação, aumentaram também as demandas subjetivas e objetivas do grupo infantil, englobando os familiares-cuidadores e os profissionais de saúde. Nesse contexto, define-se familiarescuidadores como sendo aQuelas pessoas Que mantêm laços afetivos com a criança e são reconhecidos pela unidade de saúde como responsáveis pelos cuidados ${ }^{(3)}$.

As demandas subjetivas envolvem as vivências emocionais, sentimentais e afetivas do familiar-cuidador frente à contaminação da criança pelo HIV, Que podem interferir diretamente no seu papel de prestar o cuidado. O conhecimento do diagnóstico da criança pela família representa um momento de confirmação da passagem de uma condição para outra: da saudável para a infectada, levandoa a depender de medicamento para viver. Sentimentos de raiva, frustração e desespero podem acometer esse núcleo social a partir da revelação diagnóstica e das mudanças no estilo de vida. A relação imediata Que se estabelece entre HIV/AIDS e comportamentos moralmente inadequados, expondo-a a julgamentos alheios, é outro fator complicador ${ }^{(4)}$

Associado a isso, a necessidade da terapia anti-retroviral (TARV) expõe a soropositividade da criança em seu meio social e constitui uma vivência com os estigmas e os preconceitos estabelecidos pela sociedade. Tanto ela, como suas famílias e entes Queridos passam a conviver com os desafios constantes emergentes dessa realidade, com os Quais precisa enfrentar no cotidiano das instituições, como por exemplo, a escola. O estigma e o preconceito têm gerado um muro de silêncio ao redor das famílias de crianças HIV positivas em decorrência do medo de possíveis discriminações em seus cotidianos. Ademais, propicia situações em Que a soropositividade e/ou a TARV da criança ou seus familiares necessitam ser mantidos ocultas frente aos desafios de viver com o HIV, a possibilidade de adoecer e o conviver em sociedade ${ }^{(5)}$.

No conjunto das demandas objetivas está o provimento, para o familiar-cuidador, de suporte financeiro, pois o Programa da TARV ${ }^{(2)}$ distribui os medicamentos necessários à terapia específica da criança portadora do HIV sem custos para a família. Apesar disso, ambos continuam requerendo recursos financeiros para cobertura de custos relacionados à terapia complementar (anti-fungicos, polivitamínicos, antibióticos, dentre outros). Por outro lado, ainda, há demandas cognitivas e de enfrentamento na implementação de ambas as terapias, nos espaços público e privado.

A partir desse contexto, apresentam-se as seguintes Questões de pesquisa: como se dá o cotidiano de familiares e/ou cuidadores de crianças Que utilizam a TARV? Que dimensões estão presentes nas situações existenciais da implementação do cuidado medicamentoso? Para responder a essas Questões, foram traçados os seguintes objetivos: desvelar o cotidiano de familiares e/ou cuidadores de criança em TARV e analisar as dimensões das situações existenciais do familiar-cuidador na implementação do cuidado medicamentoso à criança em terapia antiretroviral.

Destaca-se, ainda, a importância deste estudo em função das dificuldades encontradas pelos profissionais e pelas unidades de saúde para entrarem e compreenderem o universo simbólico Que contextualiza esses familiares. Ao mesmo tempo, torna-se relevante explicitar a subjetividade desses cuidadores para Que intervenções possam ser realizadas no sentido de aumentar a adesão à TARV.

Os referenciais teóricos de ocultamento ${ }^{(6)}$, silêncio ${ }^{(7)}$, silenciamento $^{(8)}$ e educação dialógica ${ }^{(7)}$ foram adotados para conduzir o processo de desvelamento e análise do cotidiano dos familiarescuidadores diante da TARV.

O ocultamento se deve ao social infiltrado no organismo do enunciador e compreende estratégias de enunciação normalmente impregnadas de ironia ou resistência, como conseqüência do entrecruzamento de duas dimensões discursivas, a exterior e a interior. Dessa maneira, este fenômeno está na origem da particularidade das construções das frases, das rupturas de sintaxe e das especificidades do estilo Que permitem ocultar, esconder ou não explicitar algo Que se apresenta ideologicamente rechaçado, mas presente na vivência e no discurso interno dos sujeitos ${ }^{(6)}$. O silêncio pode ser compreendido com o sentido de tragédia, pois não constitui novas formas de enunciação, eliminando as possibilidades de sustentação do diálogo $0^{(7)}$.

Ao mesmo tempo, apresenta-se como constituidor e mantenedor do diálogo entre os sujeitos comunicantes, na perspectiva da análise do discurso. A respeito do último, distingue-se dois tipos: o silêncio fundador e a política do silenciamento ${ }^{(8)}$. O primeiro é tido como o princípio de toda significação, ou seja, a própria condição de produção do sentido. Dessa maneira, ele aparece como o espaço diferencial da significação, lugar Que permite a linguagem significar. $\mathrm{Na}$ política do silenciamento, ao contrário, encontra-se a cisão entre o Que pode ser e o Que não pode ser dito, aspecto que o diferencia do fundador, pois neste caso o silêncio significa por si mesmo. A política do silenciamento desdobra-se em duas formas de existência: o silêncio constitutivo e o local; o primeiro age como um efeito de sentido denominado de anti-implícito, se dizendo " $x$ " para não dizer " $y$ "(8). O silêncio local apresenta-se como interdição do dizer, coibindo e proibindo o que se diz. No interior desse contexto, cabe resgatar a noção de política do silenciamento, especialmente através da censura, pois parece que é esta forma Que perpassa, com maior peso, o dito e o não-dito do enunciador.

A educação dialógica tem como característica a crítica reflexiva da realidade, visando a realização de uma intervenção na mesma para a sua transformação(7). A essência problematizadora, democrática e crítica dessa modalidade de educação faz com Que o educando seja um co-responsável pela sua educação e o educador um facilitador no encontro das respostas para os problemas. 


\section{MÉTODO}

Quanto ao desenho da peseuisa, a abordagem eualitativa foi adotada para conduzir a produção e análise de dados. Entre os métodos Qualitativos, optamos pelo criativo e sensível( ${ }^{(9)}$ porque se privilegiou a crítica reflexiva e a estratégia da dinâmica grupal entre os participantes da pesquisa, levando-os a interagir e a dialogar sobre suas vivências e experiências. Destaca-se a utilização das Dinâmicas de Criatividade e Sensibilidade (DCS) como a linha axial do método, combinado às produções artísticas delas decorrentes ${ }^{(9)}$. No interior das DCS acontecem a entrevista coletiva, a discussão de grupo e a observação participante, mediada pela crítica reflexiva freiriana típica do círculo de cultura ${ }^{(7)}$, visando produzir dados para pesquisa.

O cenário de estudo foi uma unidade de saúde ambulatorial, pública, universitária, do Município do Rio de Janeiro, de referência para o atendimento à criança portadora do HIV/AIDS e sua família. O grupo de pesquisa foi constituído por sete familiares-cuidadores de crianças com necessidades especiais de saúde, HIV positivas, e foram respeitados os seguintes critérios de inclusão: ser familiarcuidador de crianças em uso contínuo de TARV no domicílio e atendido na unidade supracitada. Para garantir o anonimato dos sujeitos, adotaram-se pseudônimos indicados por eles mesmos (Denise, Patrícia, Soraia, Marina, Joel, Zilda e Sônia) e a enunciação das crianças no discurso dos participantes foi marcada no texto em ordem alfabética de aparecimento (A, B, C, D, e E). Destaca-se Que o número de crianças não é igual ao de cuidadores porque tanto o Joel Quanto a Zilda cuidam da mesma (Quadro 1).

Para a produção de dados, realizou-se a dinâmica do concreto com sete participantes, distribuídos em dois encontros no mês de novembro de 2004, nas dependências do Laboratório de Pesquisa e Tecnologia Educacional em Saúde da Criança (LAPTESC), do Núcleo de Pesquisa em Saúde da Criança da Escola de Enfermagem Anna Nery, Universidade Federal do Rio de Janeiro. Os participantes da pesquisa responderam a duas Questões geradoras de debate: (a) o que eu tenho feito para que meu filho tome o remédio? (b) o Que ele ou ela sente depois Que toma o remédio?
A dinâmica do concreto inspira-se nos princípios do role play ${ }^{(9)}$, tendo como característica central a explicitação do cotidiano do familiar e/ou cuidador na implementação de alguma prática de cuidar como um evento do cotidiano ${ }^{(8)}$. No estudo em tela, eles demonstraram e falaram sobre suas práticas no cuidado à criança em uso de TARV. Cada dinâmica desenvolve-se em cinco momentos distintos: (a) o acolhimento e apresentação do ambiente da pesQuisa; (b) a apresentação dos participantes do grupo e a explicação sobre o encontro; (c) a enunciação e a discussão das Questões geradoras de debate; (d) a dramatização e análise individual; e (e) análise e validação coletiva das produções individuais e do role play.

As dinâmicas foram gravadas em audiotape e videotape, gerando um relatório Que se constituiu na fonte primária dos dados, após a transcrição das fitas. Posteriormente, conferiram-se materialidades lingüísticas ao texto, aproximando a produção verbal das circunstâncias em Que foram enunciadas. Aplicou-se, em seguida, os dispositivos analíticos da análise de discurso ${ }^{(8,10)}$, com destaque para o silenciamento, a paráfrase, a polissemia e a metáfora, objetivando extrair a produção de sentido constituída pelos sujeitos a partir do material transcrito.

Nesse sentido, ressalta-se Que o funcionamento da linguagem e a produção de sentido se assentam e se fundamentam na tensão entre os processos parafrásticos e polissêmicos ${ }^{(8,10)}$. Os parafrásticos são entendidos como aQueles pelos Quais em todo dizer há sempre algo Que se mantém, o dizível, a memória, enQuanto a polissemia é definida como o deslocamento, a ruptura na continuidade perpetrada pela paráfrase, jogando permanentemente com o equívoco.

Para esses autores, o efeito metafórico é imprescindível neste tipo de análise, pois é constitutiva do processo de produção de sentido e da constituição dos sujeitos. A metáfora pode ser entendida como figura de linguagem, ou ainda, pela tomada de uma palavra por outra através de um mecanismo de transferência, estabelecendo o modo como as palavras significam. Nos sujeitos, a metáfora se tornou fundamental, pois ela organizou o seu processo discursivo. Isso se refletiu no fato de Que palavras como problema, doença, isso ou a expressão isso aí poderiam ser substituídas por

\begin{tabular}{|c|c|c|c|c|c|}
\hline \multicolumn{2}{|c|}{ Identificação do Familiar Cuidador } & $\begin{array}{l}\text { Iniciais } \\
\text { da }\end{array}$ & $\begin{array}{l}\text { Renda } \\
\text { Pessoal }\end{array}$ & $\begin{array}{l}\text { Renda } \\
\text { Familiar }\end{array}$ & Profissão \\
\hline \multirow{2}{*}{$\begin{array}{l}\text { PRIMEIRA } \\
\text { DINÂMICA } \\
\text { CONCRETO }\end{array}$} & $\begin{array}{l}\text { Denise . } 20 \text { anos. Irmã. Não tem } \\
\text { religião. Não informou a escolaridade }\end{array}$ & A. & - & $1.000,00$ & Do lar \\
\hline & $\begin{array}{l}\text { Patrícia. } 53 \text { anos. Tia. Evangélica. } 3^{\text {a }} \\
\text { Série do Ensino Fundamental }\end{array}$ & B. & 520,00 & $\begin{array}{l}\text { Não Sabe } \\
\text { Informar }\end{array}$ & Diarista \\
\hline \multirow{5}{*}{$\begin{array}{l}\text { SEGUNDA } \\
\text { DINÂMICA } \\
\text { CONCRETO }\end{array}$} & $\begin{array}{l}\text { Soraia. } 5 \mathrm{I} \text { anos. Avó. Evangélica } \\
\text { Ensino Fundamental Completo }\end{array}$ & C. & - & 260,00 & Do lar \\
\hline & $\begin{array}{l}\text { Marina. } 30 \text { anos. Prima. Católica } \\
\text { Ensino Médio Completo }\end{array}$ & C. & 305,00 & 305,00 & Do lar \\
\hline & $\begin{array}{l}\text { Zilda. } 63 \text { anos. Tia-avó. Evangélica. } 3^{\mathrm{a}} \\
\text { Série do Ensino Fundamental }\end{array}$ & D. & 260,00 & 520,00 & Do lar \\
\hline & $\begin{array}{l}\text { Joel. } 37 \text { anos. Vizinho. Testemunha de } \\
\text { Jeová. 7a Série do Ensino Fundamental }\end{array}$ & D. & 380,00 & 380,00 & Mecânico \\
\hline & $\begin{array}{l}\text { Sônia. } 54 \text { anos. Avó. Evangélica } \\
\text { 5a Série do Ensino Fundamental }\end{array}$ & E. & 800,00 & 800,00 & Costureira \\
\hline
\end{tabular}

Quadro 1. Caracterização dos sujeitos. 
HIV ou AIDS, fornecendo o verdadeiro sentido para as palavras citadas.

Do corpus dos textos foram demarcadas as situações existenciais em uma série de Quadros analíticos procurando explicitar os mecanismos de produção de sentido utilizados pelos sujeitos em sua discursividade, abrangendo o seu dito e o não-dito. Os Quadros analíticos permitiram a codificação das dimensões e das temáticas, bem como a sua descodificação (formação de subtemas) e a recodificação (síntese da temática ou da dimensão) ${ }^{(9)}$.

Ressalta-se Que o projeto foi aprovado pelo comitê de ética (aprovação CEP EEAN/UFRJ No 013/04 de 31/08/2004) e Que todas as recomendações éticas constantes da Resolução 196/96 do Conselho Nacional de Saúde/Ministério da Saúde foram obedecidas. Neste sentido, sem prejuízo das demais ações, a entrada em campo se deu somente após a autorização institucional dos seus responsáveis e os dados eram coletados após a exposição dos objetivos e do percurso metodológico da pesquisa aos sujeitos e à assinatura do Termo de Consentimento Livre e Esclarecido.

\section{RESULTADOS E DISCUSSÃO}

As dimensões do ocultamento ${ }^{(6)}$, do silenciamento ${ }^{(8)}$ e do silêncio ${ }^{(7)}$ apresentaram-se transversais aos processos discursivos dos diferentes sujeitos do estudo. Essas dimensões foram codificadas pelos familiares-cuidadoras através das diversas situações existenciais no decorrer das dinâmicas realizadas. Denise foi uma das participantes a codificar o ocultamento:

Pesquisador (trago a Denise para o cerne da discussão e pergunto): Denise, como é Que foi no início (do tratamento) pra você?

Denise: $A$ A (referindo-se à criança), no inicio, Quem acompanhava ela no médico era a minha mãe, porQue eu ainda era nova. Mas eu vinha com ela. Então, assim... Quem mais cuidava assim, era a minha mãe, Que Quando ela veio a saber, ela já tinha..., foi Quando ela (A) teve um tombo... Quando ela tinha sete meses, ela não tem um pedaço de osso na cabeça. Foi aí Que eles... Que descobriu que ela tinha isso, porque isso aqui dela (Denise aponta para o seu maxilar inferior e a região das parótidas), essas glândulas inchavam, aí a minha mãe levou ela no médico e o médico falou que achava que era por causa das glândulas dela.

O discurso dessa familiar é marcado por regularidades (ou pistas) linguísticas ${ }^{(8,10)}$ Que mantém o HIV/AIDS em estado de ocultamento. Observa-se, portanto, Que os termos HIV ou Aids não estão presentes em seu dizer, apesar de o fenômeno central ser a descoberta da soropositividade da sua mãe e da sua irmã (A).

Portanto, ao empregar as expressões isso, a doença e o problema, sem exteriorizar o seu diálogo interior relacionado ao HIV/AIDS, a familiar mantém as expressões encobertas, ocultas, através do processo metafórico. Tal fato advém da representação social do HIV/AIDS na sociedade, ainda marcado pela imagem da morte e pelo estigma, dificultando a sua enunciação(1 I), inclusive entre pessoas Que estão convivendo com a mesma problemática, como é o caso dos participantes do grupo de pesquisa. Assim, observa-se a incompletude linguística à medida Que ocorre uma não explicitação do Que foi diagnosticado a partir do evento da Queda.

A situação existencial revela Que o ocultamento possui três faces: a não exteriorização do discurso interior do HIV/Aids, a soropositividade da mãe e a soropositividade da criança. A familiar continua:

Denise: Aí fez o exame (do HIV) Que deu positivo. Ailí a minha mãe Que começou a fazer o tratamento, porQue eu era nova... Aí, agora tem cinco anos Que a minha mãe morreu...

Novamente, em sua enunciação, oculta em seu dizer a Qual tipo de exame a criança foi submetida, pois ela sabe Que ao dizê-lo estará revelando uma face oculta da síndrome em sua vida - a soropositividade. Ao mesmo tempo em que se destacou que o exame realizado em $\mathrm{A}$. deu positivo, não foi especificado a Que tipo de teste foi submetida. Percebe-se, portanto, o ocultamento como uma Questão recorrente na discursividade da familiar, à medida Que a expressão exame do HIV se revela pelo não-dito e pelas condições de produção do discurso de todos os envolvidos na dinâmica do concreto.

A situação existencial também revela o drama familiar em decorrência da morte da mãe. Em nenhum momento é exteriorizada a expressão HIV/Aids associado à morte da mãe, mas as condições de produção do discurso e a observação informam de Que foi em conseqüência do agravamento da Aids.

A Patrícia também codifica o ocultamento como uma dimensão da sua discursividade:

Pesquisador: E alguma vez ela (A) não Quis tomar o medicamento? Denise: Não. Sempre Quis, sempre tomou. [...] Pouco tempo, Que ele (B) começou a falar: Por que eu tomo medicamento? Por que... Que eu tenho Que tomar... todo mundo... ninguém toma, só eu Que tenho que tomar medicamento? Ele fica só reclamando, né? Tem um outro também Que ele toma, é...Cadê? É o de $21 \mathrm{ml}$...(o AZT)

A enunciação da familiar com relação à dificuldade com o cuidado medicamentoso apresenta-se tensionada entre o passado e o presente. No passado, ela nunca enfrentou nenhum problema. $\mathrm{Na}$ atualidade, a criança, com nove anos, tem Questionado a razão do uso continuado do medicamento e a obrigação de fazê-lo, haja vista Que outras pessoas da casa e as demais crianças com Quem convive não o utilizavam. Além disso, parece Que o B se aborrece com essa situação, pois fica reclamando.

Ainda assim, a participante não esclarece o que ela responde à indagação e à indignação do filho, assim como muda de assunto rapidamente retornando à enunciação relativa aos medicamentos. No Que tange à relação da mãe com o filho há um silenciamento ao não responder com clareza sobre o Questionamento da criança acerca da necessidade do uso contínuo do medicamento e à constatação de Que as demais pessoas não fazem uso do mesmo.

A enunciação da criança, na narrativa da familiar, apresenta-se com duas incompletudes, ambas relacionadas ao uso continuado dos medicamentos e à tensão entre locuções adverbiais todo mundo e ninguém no uso do medicamento. Cabe destacar, ainda, Que 
essa enunciação se insere no discurso da familiar através da polifonia ${ }^{(6)}$, onde a mesma traz à cena a voz da criança.

As duas familiares dão continuidade às suas discursividades

Pesquisador: Vocês acham Que o medicamento atrapalha a vida das crianças ( $A$ e $B$ ).

Denise (dessa vez, começa a falar): Acho Que... assim... às vezes, sim, porque na hora de sair, pra certos tipos de lugar que gente vai, aí deu a hora de dar remédio, a gente não pode passar da hora, tem que dar naquela hora... e as pessoas ficam olhando, $e$ fica perguntando:_o Que é isso? (Curiosos com relação ao medicamento)

Mediada por processos parafrásticos, a familiar revela Que o medicamento atrapalha o cotidiano social da criança e de seus familiares e/ou cuidadores à medida Que expõe a condição de soropositividade, assim como a situação existencial vivenciada pela família diante da sociedade ${ }^{(12-13)}$. Contudo, não são todos os lugares em Que isso ocorre, embora essa diferenciação não tenha sido apresentada por ela.

O atrapalhar do medicamento na vida das crianças e suas famílias tem correlação com o fato de as pessoas presenciarem a ingestão do mesmo, tornando público o Que é realizado de forma privada pela família. Os medicamentos antiretrovirais adeuirem uma necessidade de serem ingeridos de forma escondida, não explícita, especialmente em função de possíveis perguntas oriundas de eventuais observadores. Neste contexto e para esse grupo, os antiretrovirais passam a ser um signo social identificador do HIV/ AIDS $^{(6)}$.

A Denise prossegue explicando o Que diz Quando lhes Questionam sobre o uso do medicamento:

Denise: Da A eu falo, porque ela teve esse problema, Que ela caiu. Aí falam: Ah, ela toma remédio, por que ela tem problema na cabeça? Aí, eu mostro onde tem a fratura. PorQue o médico falou Que Quando ela tiver 23 anos se não tiver fechado, ela vai ter que operar novamente. Aí eu dou essa desculpa, porque todo mundo fica perguntando (acerca do medicamento que A. toma). Até em casa mesmo! Às vezes tá na hora de dar o remédio, chega alguém aí pergunta: Ai, o Que é isso que ela (A) tá tomando? (...) Aí minha vó fala também, aí fala. (...) Então, às vezes, a gente Quer sair, vai pra uma praia, o remédio que ela (A) toma (d4T), um só pode tomar gelado, é direto na geladeira (d4T). Se vai pra uma praia tem que enfiar tudo dentro do gelo. Se vai sair pra casa de alguém, chega lá tem Que pôr na geladeira. Eles ficam perguntando: o que é isso? O ruim é esse../ essa parte...

Quando a familiar é Questionada por aqueles Que observam o cuidado medicamento, ela antecipa Qual é a reação dessas pessoas em determinadas situações, ou seja, sustenta o seu ocultamento mediado pelo processo de antecipação ${ }^{(6)}$. Ao mesmo tempo, amplia a resposta, comentando acerca da patologia Que a criança possui e não respondendo à pergunta relativa à substância ingerida. $\mathrm{O}$ discurso de Denise apresenta-se polifônico e interdiscursivo, incluindo a enunciação do profissional de saúde para dialogar com os observadores/curiosos acerca do cuidado medicamentoso. Ao proceder dessa forma, utiliza a desculpa como uma estratégia para manter o diagnóstico de soropositividade da criança oculto da vida social e assim protege a si mesmo e a criança do estigma e do preconceito.

Esse atrapalhar Que aparentemente acontecia somente nos ambientes públicos, também se dá no âmbito privado da família, dentro da própria residência, Quando algumas pessoas perguntam acerca do medicamento utilizado. O ocultamento aparece, então, não somente como um comportamento individual de uma familiar, mas uma maneira específica desse grupo se mover com o objetivo de evitar a revelação do diagnóstico sorológico.

Patrícia, também, expõe a sua situação existencial:

Patrícia: Ah, eu sempre saio depois do medicamento (administra a medicação antes de sair). Sempre volto antes do outro (referese à dose do medicamento). Só quando, lugar que tem Que dormir, aí eu adianto um pouQuinho (a dose do medicamento). Quando eu tenho que sair às II horas, dou às 10 horas o remédio, né? Porque é melhor dar adiantado, do Que não dar, né? Então, eu já dou logo adiantado a ele (B), e vou tranqUila.

As atividades externas ao lar são organizadas em função do horário do medicamento, sai depois deles e retorna antes da próxima dose, apesar de não existir recomendações especiais para a sua ingestão. Essa atitude revela-se como uma estratégia de ocultamento do medicamento e da síndrome, permeando o cotidiano do núcleo familiar. Em algumas situações é necessário adiantar o horário, revelando um discurso tensionado entre oferecer o medicamento adiantado ou não oferecê-lo publicamente, evitando a exposição da soropositividade ao público.

Nessas situações existenciais, o ocultamento esteve presente nas relações internas da família dos cuidadores (soropositividade da mãe da A.), na relação com a criança (não explicação do motivo pelo Qual se toma o medicamento) e na interação com o meio social. Há sempre uma preocupação em evitar pessoas estranhas na hora do cuidado medicamentoso, organizar as atividades de acordo com o horário das medicações ou vice-versa e de justificar a ingestão dos medicamentos, como se olhos vigilantes supervisionassem suas ações. Observa-se, então, Que este ocultamento perpassa as várias facetas do cotidiano e da vida dos familiares.

Ao lado do ocultamento, o silêncio apresenta-se como uma dimensão Que também perpassa o cotidiano desses familiares, especialmente em sua relação com as crianças assistidas. Soraia, em seu processo discursivo, codifica essa dimensão:

Pesquisador: Quando às vezes ele pergunta (o motivo de tomar o medicamento)...

Soraia: Bom, eu falo... eu respondo/... eu nem respondo nada! Fico Quieta e digo: você (C) tem Que tomar o remédio! Ele diz: Ah! É vó, então tá! Mas tem um gosto tão ruim esse remédio. Mas tem Que tomar, meu filho! Aí ele bebe. Mas eu também não falo, não converso nada com ele o Que ele tem, nada disso! Ele ainda é muito pequeno, não vai entender, né? Com Quatro aninhos ele não vai entender nada.

Observa-se a presença do silêncio da familiar frente ao Questiona- 
mento da criança, bem como a explicitação de Que se mantém silenciosa. Organiza mentalmente sua resposta à pergunta, racionalizando movimentos discursivos de repetição até explicitar o efeito de sentido de seu dizer. Nesse sentido, mediada por processos parafrásticos, revela sua crença na impossibilidade de Que a criança compreenda sobre a necessidade de tomar o medicamento em virtude de sua imaturidade. Observa-se, também, Que à semelhança de Soraia, os demais participantes possuem um discurso marcado por uma coesão linguística relacionada à abrangência de causas e conseQuências e não a orações explicativas. Pode-se considerar Que essa particularidade linguística seja consequência da presença do silêncio como organizador da formação discursiva dos sujeitos.

No decorrer desta dinâmica, outro sujeito (Joel) expõe a sua experiência:

Joel: lá falei o seguinte: $D$, você tem um... um problema/, você ta tomando esse remédio aqui (apesar de falar "aqui" ele não aponta nenhum medicamento), não é Que é normal porQue eu não estou tomando esse remédio, sua vó não está tomando, você que está tomando! Por que você está tomando esse remédio? PorQue você precisa tomar esse remédio. Uma vez ele falou assim: Pôxa, mas eu tomo esse remédio já há um tempão. Então... o Que acontece? Eu falei com ele o seguinte: Mas, veja bem, tem gente que ta cuidando de você, a gente chega lá (referindo-se à unidade de saúde)... Pra sua tia lá (referindo-se à médica), ela não cuida de você direitinho? Eu Queria ter uma pessoa para cuidar de mim assim direto... você ta cheio de cuidado de pessoal... [... Ele vai... Vai ficando... Vai analisando... Porque que... Chega na casa de uma criança, aparentemente ninguém toma remédio, só ele que toma... Ele fica... Tem hora Que eu vejo que ele fica assim... meeeio... Triste, entendeu? Aí chegou o D., vem cá, porque ela (apontando para Zilda) segura mais um pouco ele... às vezes eu chamo, eu saio, vai para uma praia, uma viagem, chamar ele, mas ela segura mais ele... Não vai à praia não... Ele tem Que crescer normal.

A discursividade do Joel reforça o dito de Soraia, em que o silêncio apresenta-se como uma estratégia adotada pelos familiarescuidadores na mediação das informações prestadas às crianças. Esse silêncio toma lugar na negociação, pois o cuidado pessoal relacionado ao medicamento se apresenta como uma recompensa, um zelo da família Que deve ser reconhecido e gratificado pela criança em troca de sua adesão ao medicamento.

A discursividade do Joel explicita a tensão entre a paráfrase e a polissemia. Ou seja, ao mesmo tempo em Que mantém a matriz do seu dizer através do silenciamento, paráfrase do próprio comportamento social com relação ao HIV/AIDS, apresenta uma ruptura nesse processo discursivo ao considerar a necessidade Que o D tem de crescer de forma normal, utilizando a polissemia para concretizar a construção frástica.

A Sônia expõe a sua situação de silêncio e ocultamento ao falar sobre o cuidado cotidiano na relação com a neta $E$ e outros familiares.

Sônia: Cuidado eu tenho. Eu não deixo ficar (a E) muito tempo na piscina, né? Por causa da pneumonia... Ela ficou muito ruim internada por tantos dias. Então, muitas coisas eu tenho cuidado: água muito gelada: não deixo beber, tempero a água. [...] Ela toma o medicamento. E eu converso com ela, Que ela tem problema no coração e se ela não tomar, ela morre. Então! Você tem Que tomar, se não tomar, vovó vai ficar triste com você. Então ela toma. E todo mundo da minha família... Muitas pessoas Que sabem realmente são muito chegadas a mim. Tem irmãos meus Que não sabem o Que ela (E) tem... sabem Que ela tem um problema no coração.

O ocultamento se manifesta Quando parte dos familiares tem conhecimento sobre o diagnóstico da neta. Já o silenciamento se apresenta na relação com a criança Quando Questionada sobre o uso contínuo do medicamento. Apesar de o diálogo ser sustentado, ele se funda no silêncio ao não se explicitar o nome do medicamento e a que ele realmente se destina. No Que tange à síndrome, substitui o seu dizer denominando-a por uma doença não-transmissível, com o abrandamento ou até mesmo a eliminação de Questões como culpabilização, responsabilização, identificação da origem de transmissão e possibilidade de contágio, entre outras coisas ${ }^{(13)}$.

A discursividade revela Que o silêncio, o silenciamento e o ocultamento se expressam de três formas: na relação com a criança; com outro familiar e com outras pessoas da comunidade .

No primeiro, o silêncio se trava na relação do familiar-cuidador com a criança manifestando-se como um tema trágico ${ }^{(7)}$, pois ele não permite a constituição de sentido, e nem a compreensão da criança sobre a sua condição HIV positiva. As interrogativas da criança, nesse sentido, mantêm-se na trajetória de vida do núcleo familiar.

O silêncio, nesse caso, possui correlação com a discursividade da familiar acerca da síndrome, ao substituir a AIDS por uma doença cardíaca. Esse silêncio acerca do HIV caracteriza-se como um tema trágico na medida em Que faz parte do seu crescimento sem Que tenha idéia da condição Que traz consigo. Ela cresce acreditando Que tem uma doença crônica, porém de caráter não-transmissível. Isso está carregado de implicações e responsabilidades éticas e sociais, em Que participa dessa trama, tanto o profissional de saúde como seus familiares, trazendo todos os riscos associados à sexualidade na adolescência ${ }^{(12-13)}$.

Ao mesmo tempo, o silêncio se perpetua na formação imaginária dessas crianças acerca das contradições presentes nos discursos dos familiares-cuidadores, no uso constante das medicações, nas visitas contínuas à unidade de saúde e na existência de siglas como HIV e AIDS no interior desta em cartazes e quadros. Esses fatos podem configurar-se de forma ambígua, incerta e angustiante, associados a punições (e, conseQUentemente, a erros cometidos) ou a injustiças (já que não fez nada para merecer tais coisas).

Já o silenciamento ${ }^{(8)}$ se faz presente Quando ao acompanhar a criança na consulta com o médico, estabelece com esse profissional uma relação dialógica Que não permite à criança participar do jogo discursivo $^{(14)}$.

O silenciamento se concretiza na não explicitação do HIV/AIDS como justificativa para o uso constante e prolongado dos fármacos, impedindo a construção de uma relação dialógica entre a cuidadora e a criança cuidada. Como consequência, construiu-se uma discursividade imperativa Quanto à obrigatoriedade do uso do medicamento, excluindo-se enunciações explicativas na formação 
discursiva da familiar. Ela, objetivando a manutenção desse fenômeno, empreende enunciações com a criança pautando-se na tragédia da morte (coação) e no amedrontamento (através da possibilidade de entristecer a Quem se ama). Esse fato gera sentimentos de culpa na criança, interrompendo o seu dizer e constituindo, conseQuentemente, o processo de silenciamento para as duas personagens envolvidas (a familiar e a criança).

O ocultamento, por sua vez, apresenta-se nas suas relações com as demais pessoas da comunidade, incluindo alguns familiares, amigos, vizinhos e pessoas de outras instituições, na tentativa de manter a soropositividade oculta. Ele se materializa na relação do cuidador com a sociedade, ressaltando Que o HIV/Aids só é revelado para pessoas "muito chegadas", excluindo desse rol laços próximos de consanguinidade, como os seus irmãos. Para a sociedade, o HIV/Aids permanece oculto através da doença cardíaca, escondendo a origem da infecção e as situações moralmente indesejáveis, bem como justificando o uso prolongado dos medicamentos.

Nesse sentido, alguns autores ${ }^{(5,15)}$ trazem uma outra contribuição à discussão sobre o silêncio, ao entendê-lo como tema trágico. À medida Que os familiares e/ou cuidadores apresentam o silêncio como transversal em seus movimentos discursivos, abrem espaços para situações complexas e literalmente trágicas, como préadolescentes Que pensam possuir uma disfunção cardíaca e tendem a iniciar a vida sexual com essa percepção.

\section{CONSIDERAÇÕES FINAIS: PONTUANDO ALGUMAS QUESTÕES IMPORTANTES}

As dimensões do ocultamento e do silenciamento se apresentaram como parte do cotidiano desses familiares em suas relações com a sociedade e com a própria criança cuidada. Compreende-se Que esses mecanismos ou fenômenos estão na base de uma forma específica de enunciação. Essa formação discursiva particular se conformou na não utilização das expressões relacionadas ao HIV/ AIDS, antiretroviral e síndrome, dentre outras, na não adjetivação dos exames e dos medicamentos ou na ausência de referentes nas enunciações em Que essas expressões ou siglas se configurariam como sujeitos oracionais, através dos processos parafrásticos, polissêmicos e metafóricos.

O silêncio e o ocultamento, no entanto, se apresentam como resultado de uma construção social, representacional e imaginária do HIV/AIDS Que se mantém presente entre essas famílias e a sociedade. Ao mesmo tempo, parece ser interiorizado pelos familiares, motivo pelo Qual aconteceram no âmbito dialógico das dinâmicas de criatividade e sensibilidade e em suas relações com as próprias crianças. Nesse contexto, destaca-se a educação dialógica em saúde ${ }^{(7.9)}$ como uma ferramenta indispensável para a superação dessa situação vivenciada pelos sujeitos. O enfermeiro se insere, então, como um educador contribuindo para o aperfeiçoamento do processo educativo implementado com os familiares e as suas crianças, mediando esse processo através do diálogo ${ }^{(16-17)}$. Ao negociar o seu conhecimento científico, realizando uma aliança de saberes ${ }^{(9)}$, esse profissional ensina e aprende através de uma dialogicidade Que constrói o outro (os familiares) como sujeito de sua história, bem como do cuidado à criança sob sua responsabilidade.

Ressalta-se, ainda, Que os dados demonstram a influência dos fenômenos expostos no cotidiano de cada família e na adesão à terapêutica instituída pela unidade de saúde. Esses fenômenos não se configuram como um elemento ao lado dos demais, mas caracteriza-se por organizar este mesmo cotidiano, conferindo-lhe uma dinâmica específica. Torna-se importante Que os profissionais os considerem como variáveis Que influencia na Qualidade de vida e no nível de saúde das crianças cuidadas.

\section{REFERÊNCIAS}

I. Praça NS, Latorre MRDO. Saúde sexual e reprodutiva com enfoQue na transmissão do HIV: práticas de puérperas atendidas em maternidades filantrópicas do município de São Paulo. Rev Bras Saúde Materno Infantil 2003; 3(1): 61-74.

2. Ministério da Saúde (BR). Boletim epidemiológico AIDS/DST. Brasília: Ministério da Saúde; 2004.

3. Elsen I. Desafios da enfermagem no cuidado de famílias. In: Elsen I, organizadora. Marcos para a prática de enfermagem com famílias. Florianópolis: Editora UFSC; 1994. p. 61-77.

4. Repetto MA, Souza MF. Congruência entre o enfermeiro e o paciente com síndrome da imunodeficiência adQuirida Quanto aos conceitos: percepção da doença e imagem corporal. Acta Paul Enferm 1999;12(2): 85-93.

5. Souza AS, Kantorski LP, Bielemann VL. A AIDS no interior da família - percepção, silêncio e segredo na convivência social. Acta Scientiarum Health Sci 2004; 26(1): 1 -9.

6. Bakhtin M. Marxismo e filosofia da linguagem. Problemas fundamentais do método sociológico na ciência da linguagem. São Paulo: Hucitec; 1992.

7. Freire P. Conscientização: teoria e prática de libertação. São Paulo: Moraes; 1980

8. Orlandi E. Análise de discurso: princípios e procedimentos. Campinas: Pontes; 2001 .

9. Cabral I. Aliança de saberes no cuidado e estimulação da criançabebê: concepções de estudantes e mães no espaço acadêmico de enfermagem. Rio de laneiro: Editora Anna Nery; 1999.

10. Pêcheux M. Análise automática do discurso. In: Gadet F, Hak T, organizadores. Por uma análise automática do discurso: uma introdução à obra de Michel Pêcheux. Campinas: Editora da Unicamp; 2001. p. 61-161.

1 1. Leite GS, Baby I, Mott L, Siqueira D, Coimbra, C. Estereótipos, AIDS e exclusão. In: Lent CF, organizador. Subjetividade e AIDS. Rio de Janeiro: Banco de Horas; 2000. p. 155-205.

12. Silva ALCN, Waidman MAP, Marcon SS. Adesão e não-adesão à terapia anti-retroviral: as duas faces de uma mesma vivência. Rev Bras Enferm 2009; 62(2): 213-20.

13. Souza AIJ, Silva KM, Silva M. Cuidando de famílias de crianças soropositivas no domicílio. Ciência Cuidado Saúde 2003; 2(2): 177-85.

14. Pereira AP. As vozes da condição: o jogo de silêncio entre crianças HIV positivo, seus acompanhantes e equipe de saúde [dissertação]. Rio de Janeiro: Curso de Pós-Graduação em 
Tecnologia Educacional para as Ciências da Saúde, Universidade Federal do Rio de Janeiro; 2004.

15. Gomes AMT. Silêncio, silenciamento e ocultamento na terapia anti-retroviral: desvelando o discurso de cuidadores de crianças [tese]. Rio de Ianeiro: Escola de Enfermagem Anna Nery, Universidade Federal do Rio de Janeiro; 2005.
16. Gomes AMT, Cabral IE. O cuidado medicamentoso à criança com HIV: desafios e dilemas de familiares cuidadores. Rev Bras Enferm 2009; 62(2): 252-7.

17. Miranda KCL, Barroso MGT, Silva LMS, Silva MRF. Reflexões sobre o aconselhamento em HIV/AIDS em uma perspectiva freireana. Rev Bras Enferm 2008; 61 (6): 899-903. 